\title{
Three-stage flow-shop scheduling model with batch processing machine and discrete processing machine
}

\author{
Yusuf Mauluddin ${ }^{1}$ \\ ${ }^{1}$ Sekolah Tinggi Teknologi Garut, Department of Industrial Engineering, Jalan Mayor Syamsu No 1 Garut 44151, Indonesia
}

\begin{abstract}
This study discusses the model development of three-stage flow-shop scheduling involving Batch Processing Machine (BPM) and Discrete Processing Machine (DPM). Each job passes several stages of the production process from the first stage in DPM-a, the second stage in BPM, to the third stage in DPM-b. Each job is sequentially processed in DPM-a and DPM-b. in BPM; every job is handled simultaneously at the same time. The maximum weight determines the capacity of BPM. This study uses mathematic modeling approach. The result model produced in this study is Mixed Integer Linear Programming (MILP) Model. Purpose function model is minimizing total completion time. Model testing is done by using numerical examples with several data scenarios. The results showed that the model produced was the optimum model and provided a unique schedule pattern. In the future research can be formulated the heuristic model.
\end{abstract}

\section{Introduction}

Flow-shop scheduling involving Batch Processing Machine (BPM) and Discrete Processing Machine (DPM) has been started since decades ago. The use of BPM in the process of flow-shop production does involve not only job scheduling but also determine the batch of every job. There are two schools of thought in understanding BPM [1]. First, it is understood as a machine processing a batch consisting of a number of jobs by sharing the setup process [2], [3], [4], [5], [6], [7], [8], [9], [10], [11],[12]. The processing time in this machine is the amount of processing time of every job in the batch. Second, BPM is understood as a machine processing a number of jobs in a batch at the same time whose time processing is not changing and influenced by the number of jobs in the batch [13], [14], [15], [16], [17], [18], [19], [20], [21], [22].

In this study, the BPM used is the second one. A previous study [14], has been resulting in two models of two-step flow-shop with the routing of BPM $\rightarrow$ DPM and $\mathrm{DPM} \rightarrow \mathrm{BPM}$. The model development is conducted for the three-step flow-shop with the routing of DPM-a $\rightarrow$ $\mathrm{BPM} \rightarrow$ DPM-b.

This production is inspired by tannery process [23]. Where one of the processes has the following routing: The first process is processed on a splitting machine where the raw leather is processed one by one to remove the epidermis. The second process, a number of products resulting from the splitting machine and then incorporated into the Moln machine to be processed simultaneously to remove lime. The amount of the leather put into the machine depends on the capacity of the device itself. The third process is the product is processed one by one in a saving machine to determine the thickness of the skin.

Splitting and Saving machines are both identical to DPM while Moln machine is identical to BPM. The scheduling process is necessary for the tannery to avoid overtime stacking in the pre-and post-processing areas in the BPM. The tardiness processing will damage the leather due to evaporation. Thus, minimizing total completion time of jobs is the main objective of the scheduling.

The three-step flow-shop scheduling model with the same routing and identical BPM in this study has been conducted in research by Ahmadi et al. [13]. The BPM capacity is limited by the unit number allowed in a process. In that model, the job that will be processed has the time attribute in the DPM. However, in this study, the BPM capacity is limited by the size of the unit weight. Thus, the job does not only have time attribute but also weight attribute. This model also takes the weight loss when the product is processed in DPM-a into consideration.

\section{Methodology}

Research methodology used is mathematical modeling, specifically mixed integer linear programming model involving two variables covering binary and integer [13],[14],[22],[24].

\subsection{Formulation of the model}

Illustration of DPM-a $\rightarrow$ BPM $\rightarrow$ DPM-b routing is shown in Fig. 1.

\footnotetext{
* Corresponding author: yusuf.mauluddin@sttgarut.ac.id
} 


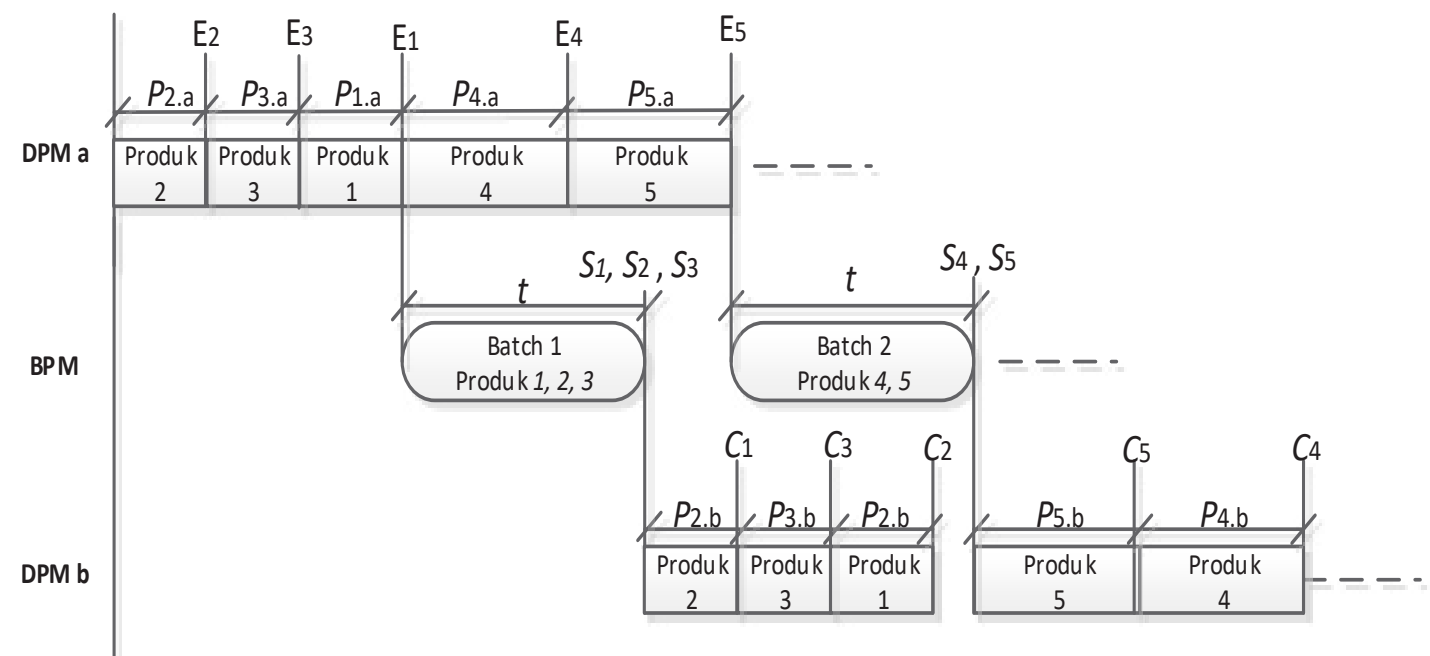

Fig. 1. Illustration of DPM-a $\rightarrow$ BPM $\rightarrow$ DPM-b routing.

Figure 1 indicates that every job is processed in DPM-a one by one for the first time, followed by the process in BPM. in which each job is handled in groups as a batch. The total weight of the jobs in that batch should have less capacity of the BPM. The process of the batch in BPM can be initiated if all the jobs in that batch have been processed in the DPM-a. When finishing the process, the jobs in the same batch will have equal finishing time value. The next process is in the DPM-b. The jobs will be processed one by one in DPM-b.

The model in this study aims to minimize total completion time in DPM-b. Thus, the decisional variables are as follows.

$Y_{i j}$ : decisional variables value 1 if the $i$ product is placed prior to $j$ product in the order of DPM-a and 0 if it is the opposite.

$Z_{i j}$ : decisional variables value 1 if the $i$ product is placed prior to $j$ product in the order of DPM-b and 0 if it is the opposite.

$W_{i j}$ : decisional variables value 1 if $i$ and $j$ products are in the same batch, and 0 if it is the opposite.

$E_{i}$ : completion time when product $i$ is finished at DPM-a.

$C_{i}$ : completion time when product $i$ is finished at DPM-b.

$S_{i}$ : completion time when product $i$ is finished BPM.

Parameters that need to be identified are

$p_{i a}: \quad$ process time of product $i$ at DPM-a;

$p_{i b}$ : process time of product $i$ at DPM-b.

$t$ : time process at BPM.

: $\quad$ product $i$ weight

$r$ : product weight percentage after process at DPM-a.

$u$ : capacity of BPM

$\mathrm{n}$ : number of products to be scheduled

$\mathrm{M}$ : big positive number

\subsection{DPM-a $\rightarrow$ BPM $\rightarrow$ DPM-b routing scheduling model}

The Mixed Integer Linear Programing Model as follow:

Purpose Function:

$$
\text { minimizing } \quad \sum_{\mathrm{i}=1}^{\mathrm{n}} \mathrm{C}_{\mathrm{I}}
$$

Limiters:

$$
\begin{aligned}
& Y_{\mathrm{i} j}+Y_{\mathrm{j}}=1 \quad \forall i_{s} j=1,2, \ldots \ldots \mathrm{n}_{s} \mathrm{i} \neq \mathrm{j} \\
& E_{\mathrm{i}}-p_{\mathrm{i} \alpha} \geq E_{j}-M Y_{\mathrm{i} j} \quad \forall i_{s} j=1,2, \ldots, \mathrm{n}_{i}^{*} \mathrm{i} \neq \mathrm{j} \\
& E_{i}-p_{i, a} \geq 0 \quad \forall i_{s} j=1,2 \ldots \ldots, \mathrm{n}_{s} \\
& W_{i j}-W_{j i}=0 \quad \forall i_{s} j=1,2, \ldots, \mathrm{n}_{w}^{*} \mathrm{i} \neq \mathrm{j} \\
& l_{i} r+\sum_{j=1}^{n} W_{i j} l_{j} r \leq u \quad \forall i_{x} j=1,2 \ldots \ldots \mathrm{n} \\
& S_{i}+M \geq S_{j}-M W_{i j} \quad \forall i_{s} j=1,2, \ldots, \mathrm{n}_{w}^{*} \mathrm{i} \neq \mathrm{j} \\
& S_{i}-t \geq E_{i} \quad \forall i_{s} j=1,2 \ldots \ldots, \mathrm{n} \\
& S_{i}-t+M Y_{i j} \geq S_{j}-t W_{i j} \forall i i_{i j}=1,2, \ldots, \mathrm{n}_{i} i \neq \mathrm{j} \\
& Z_{i j}+Z_{j i}=1 \quad \forall i i_{s} j=1,2, \ldots, n_{m} ; \neq j \\
& C_{\mathrm{i}}+p_{\mathrm{i}, b} \geq C_{j}-M Z_{\mathrm{ij}} \quad \forall i_{s} j=1,2, \ldots \ldots, \mathrm{n}_{;}, \mathrm{i} \neq \mathrm{j} \\
& C_{i}-p_{i j} b \geq S_{i} \quad \forall i_{s} j=1,2, \ldots x n \\
& Z_{i j}, Y_{i j}, W_{i j} \in[0,1] \quad \forall i_{s} j
\end{aligned}
$$

\footnotetext{
* Corresponding author: yusuf.mauluddin@,sttgarut.ac.id
} 


$$
C_{\mathrm{i}}, E_{\mathrm{i}}, S_{i} \geq 0 \quad \forall i
$$

Limiters (2), (3) and (4) are limiters of job sequence and completion time every job at DPM-a. Limiters (4) and (5) are limiters for batching process. Limiters (7), (8), and (9) are limiters completion time every job in BPM. Limiters (10), (11), and (12) are limiters of job sequence and completion time every job at DPM-b.

\section{Results and discussion}

\subsection{Results}

The resulting model is a mixed integer linear programming model [13][20]. The following numerical example is used to see if the resulting model can provide the optimum solution: Six jobs are about to be scheduled in the process of DPM-a $\rightarrow$ BPM $\rightarrow$ DPM- $b$ routing. BPM has the capacity of $20 \mathrm{~kg}$, and the time process is 25 minutes. The weight of the product is constant after being processed at DPM-a. The process time at the DPM is shown in Table 1.

Table 1. Weight $(l i)$ and time process at di DPM-a $\left(p_{i a}\right)$ and DPM-b $\left(p_{i b}\right)$ for every jobs.

\begin{tabular}{|c|c|c|c|}
\hline Product & $\begin{array}{c}\text { Process time } \\
\left(\mathbf{p}_{\mathbf{i a}}\right)(\mathbf{m i n s})\end{array}$ & $\begin{array}{c}\text { Process time } \\
\left(\mathbf{p}_{\mathbf{i b}}\right)(\mathbf{m i n s})\end{array}$ & $\begin{array}{c}\text { weight }(\boldsymbol{l i}) \\
(\mathbf{K g})\end{array}$ \\
\hline 1 & 5 & 2 & 2 \\
\hline 2 & 9 & 8 & 7 \\
\hline 3 & 12 & 11 & 6 \\
\hline 4 & 15 & 16 & 9 \\
\hline 5 & 4 & 7 & 2 \\
\hline 6 & 2 & 2 & 1 \\
\hline
\end{tabular}

With a model and a software Lingo, the optimum solution is obtained with computation time of 4 minutes and 50 seconds.

Table 2. Schedule and batch of the job for example.

\begin{tabular}{|c|c|c|c|c|c|c|}
\hline \multicolumn{2}{|c|}{ DPM a } & \multicolumn{3}{c|}{ BPM } & \multicolumn{2}{c|}{ DPM b } \\
\hline Sequence & $\mathbf{E}_{\mathbf{i}}$ & \multirow{2}{*}{ Batch } & Job & $\mathbf{S}_{\mathbf{i}}$ & Sequence & $\mathbf{C}_{\mathbf{i}}$ \\
\hline 6 & 2 & \multirow{2}{*}{1} & 5 & 31 & 6 & 33 \\
\hline 5 & 6 & & 6 & 31 & 5 & 40 \\
\hline 2 & 15 & \multirow{2}{*}{2} & 1 & 57 & 1 & 59 \\
\hline 1 & 20 & 2 & 57 & 2 & 67 \\
\hline 3 & 32 & & 3 & 57 & 3 & 78 \\
\hline 4 & 47 & 3 & 4 & 82 & 4 & 98 \\
\hline & & & & $\sum C_{i}$ & 375 \\
\hline
\end{tabular}

The scheduling results on Table 2 show that at DPMa the schedule is $6,5,2,1,3,4$. At the BPM, there are three batches. In batch 1 , there are job 5 and 6 , and it ends at 31 mins. In batch 2, their products are 1, 2, and 3 and it ends at 57 mins. In batch 3, there is product 4, and the batch ends at 82 mins. The Gantt chart for the scheduling is illustrated in Figure 2.

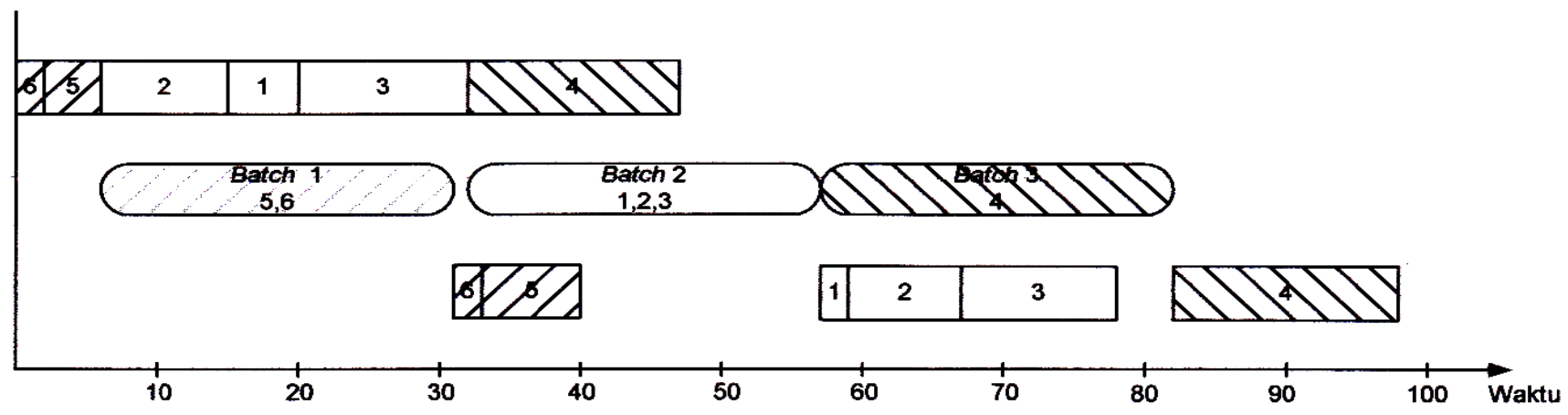

Fig. 2. Gantt chart scheduling result.

\subsection{Discussion}

The model created in this study is proven result the optimum solution but three-stage scheduling problem with BPM and DPM is a NP Complete issue [13]. It can also be proved by using lingo software, the more number of jobs scheduled, the longer computation time required.

Some researchers develop heuristic methods to solve this problem. Common algorithms used to construct heuristic models are dinamics programing[6], bee colony algorthm[19], Tabu search algorithm[20], and others[12][13] [21]. The heuristic model can also be built based on the schedule pattern generated from the optimum model.

To identify the pattern of schedule, the scenario from previous research [14] used options are as follows.

\subsubsection{Scenario 1}

The weight of every product is equal and the time process 
of every product at DPM has a small score so that the equation is as follows.

$$
\sum_{j=1}^{n} W_{i, j} p_{j} \leq t-p_{i} \quad \forall i: 1,2, \ldots, n
$$

\subsubsection{Scenario 2}

The weight of every product is equal and the process time of every job at the DPM has a big score so that the equation is as follows.

$$
\sum_{j=1}^{n} W_{i, j} p_{j} \geq t-p_{i} \quad \forall i: 1,2, \ldots, n
$$

\subsubsection{Scenario 3}

The process time of every job at DPM is the same, yet the weight is different. The time on DPM has the following equation.

$$
\sum_{j=1}^{n} W_{i, j} p_{j} \leq t-p_{i} \quad \forall_{I}: 1,2, \ldots, n
$$

\subsubsection{Scenario 4}

The process time at the DPM is the same, yet the weight is different. The process time at DPM is big so that the equation is as follow.

$$
\sum_{j=1}^{n} W_{i, j} p_{j} \geq t-p_{i} \quad \forall i: 1,2, \ldots, n
$$

The time process on the BPM has the same value in each scenario. However, the weight is assumed constant $(\mathrm{r}=100 \%)$. The analysis is done using a software Lingo version 8 . The schedule patterns are as follows:

- The schedule of product making at DPM-a and DPM-b follows the rules of Shortest Processing Time.

- the number of jobs in a batch will be maximized if the total process time in the DPM for every batch is lower than time process of BPM.

- If the time process in BPM is higher from the total process time of the batch on the DPM, the batching on the BPM is prioritized.

- If the process time on BPM is lower than the total of process time of the batch in the DPM, the scheduling job on the DPM is prioritized.

\section{Conclusions}

The result of this research is a three-stage flowshop scheduling MILP model involving BPM and DPM. The resulting model provides an optimum solution and offers a unique schedule pattern. In subsequent analysis, it is possible to construct a heuristic model.

\section{References}

1. S. Zhou, X. Li, H. Chen, and C. Guo, Minimizing makespan in a no-wait flowshop with two batch processing machines using estimation of distribution algorithm, Int. J. Prod. Res., vol. 54, no. 16, pp. 4919-4937, (2016)

2. T. C. E. Cheng, J. N. D. Gupta, and G. Q. Wang, A review of flowshop scheduling research with setup times, Prod. Oper. Manag., vol. 9, no. 3, pp. 262282, (2000)

3. B. M. T. Lin and T. C. E. Cheng, Batch scheduling in the no-wait two-machine Flowshop to minimize the makespan, Comput. Oper. Res., vol. 28, pp. 613-624, (2001)

4. T. C. E. Cheng, M. Y. Kovalyov, and K. N. Chakhlevich, Batching in a two-stage flowshop with dedicated machines in the second stage, IIE Trans. Institute Ind. Eng., vol. 36, no. 1, pp. 87-93, (2004)

5. B. M. T. Lin and T. C. E. Cheng, Two-machine flowshop batching and scheduling, Ann. Oper. Res., vol. 133, no. 1-4, pp. 149-161, (2005)

6. C. T. Ng and M. Y. Kovalyov, Batching and scheduling in a multi-machine flow shop, J. Sched., vol. 10, no. 6, pp. 353-364, (2007)

7. L. Tang and P. Liu, Two-machine flowshop scheduling problems involving a batching machine with transportation or deterioration consideration, Appl. Math. Model., vol. 33, no. 2, pp. 1187-1199, (2009)

8. H. Gong, L. Tang, and C. W. Duin, A two-stage flow shop scheduling problem on a batching machine and a discrete machine with blocking and shared setup times, Comput. Oper. Res., vol. 37, no. 5, pp. 960-969, (2010)

9. L. Shen and U. Buscher, Solving the serial batching problem in job shop manufacturing systems, Eur. J. Oper. Res., vol. 221, no. 1, pp. 14-26, (2012)

10. L. Shen, J. N. D. Gupta, and U. Buscher, Flow shop batching and scheduling with sequence-dependent setup times, J. Sched., vol. 17, no. 4, pp. 353-370, (2014)

11. M. D. Astuti and A. H. Halim, Model Penjadwalan Pada Batch Processor Tunggal Dengan Waktu Proses Total Waktu Tinggal Aktual, J. Rekayasa Sist. Ind., vol. 4, no. 1, pp. 62-67, (2017)

12. J. M. Yu, R. Huang, and D. H. Lee, Iterative algorithms for batching and scheduling to minimise the total job tardiness in two-stage hybrid flow shops, Int. J. Prod. Res., vol. 55, no. 11, pp. 32663282, (2017)

13. C. S. T. Javad H.Ahmadi, Reza J. Ahmadi, Sriram dasu, Batching and Scheduling Jobs and Discrete Processors, Oper. Res., vol. 39, no. August 2015, pp. 750-763, (1992)

14. Y. Mauluddin and H. Halim, Model Penjadwalan Job yang Diproses Serial pada Mesin Pengolah 
Batch dan Pengolah Job, pp. 392-401. (2005)

15. A. Oulamara, G. Finke, and A. Kamgaing Kuiteing, Flowshop scheduling problem with a batching machine and task compatibilities, Comput. Oper. Res., vol. 36, no. 2, pp. 391-401, (2009)

16. Y. Fang, X. Lu, and P. Liu, Online batch scheduling on parallel machines with delivery times, Theor. Comput. Sci., vol. 412, no. 39, pp. 5333-5339 (2011)

17. J. Behnamian, S. M. T. Fatemi Ghomi, F. Jolai, and O. Amirtaheri, Realistic two-stage flowshop batch scheduling problems with transportation capacity and times, Appl. Math. Model., vol. 36, no. 2, pp. 723-735 (2012)

18. S. Li, Parallel batch scheduling with inclusive processing set restrictions and non-identical capacities to minimize makespan, Eur. J. Oper. Res., vol. 260, no. 1, pp. 12-20, (2017)

19. R. Zhang, P. C. Chang, S. Song, and C. Wu, A multi-objective artificial bee colony algorithm for parallel batch-processing machine scheduling in fabric dyeing processes, Knowledge-Based Syst., vol. 116, pp. 114-129, (2017)

20. O. Shahvari and R. Logendran, An Enhanced tabu search algorithm to minimize a bi-criteria objective in batching and scheduling problems on unrelatedparallel machines with desired lower bounds on batch sizes, Comput. Oper. Res., vol. 77, pp. 154 176, (2017)

21. Y. Tan, L. Mönch, and J. W. Fowler, A hybrid scheduling approach for a two-stage flexible flow shop with batch processing machines, J. Sched., pp. 1-18, (2017)

22. B. Shahidi-Zadeh, R. Tavakkoli-Moghaddam, A. Taheri-Moghadam, and I. Rastgar, Solving a biobjective unrelated parallel batch processing machines scheduling problem: A comparison study, Comput. Oper. Res., 88, pp. 71-90, (2017)

23. M. A. Ramdhani, H. Aulawi, A. Ikhwana, and Y. Mauluddin, Model of green technology adaptation in small and medium-sized tannery industry, J. Eng. Appl. Sci., 12, no. 4, pp. 954-962, (2017)

24. E. R. Wulan, M. A. Ramdhani, and Indriani, Determine the Optimal Solution for Linear Programming with Interval Coefficients IOP Conf. Ser. Mater. Sci. Eng., vol. 288, no. 1, pp. 1-6, (2018) 